\title{
Study and results of reconstruction plating in fracture posterior column and posterior wall of acetabulum
}

\author{
Nilesh Indulal Kachnerkar ${ }^{1 *}$, Pravin Markade ${ }^{2}$ \\ ${ }^{1}$ Assistant Professor, ${ }^{2}$ Senior Registrar, Department of Orthopaedics, GMCH, Aurangabad, Maharashtra, India
}

Received: 14 September 2017

Revised: 02 October 2017

Accepted: 03 October 2017

\section{*Correspondence:}

Dr. Nilesh Indulal Kachnerkar,

E-mail: dr.smitanilesh@rediffmail.com

Copyright: $\odot$ the author(s), publisher and licensee Medip Academy. This is an open-access article distributed under the terms of the Creative Commons Attribution Non-Commercial License, which permits unrestricted non-commercial use, distribution, and reproduction in any medium, provided the original work is properly cited.

\begin{abstract}
Background: Posterior acetabulum fractures are the most common type of acetabular fractures. Acetabular fracture was an enormous orthopaedic problem in which the treatment was grossly inadequate and many patients were left with incapacitating pain. These fractures were often feared because of the poor outcome in many patients treated nonoperatively. There are few published studies with a prolonged follow up. Thus this study was to review the displaced posterior acetabular fractures treated operatively in our hospital during last 5 years with regards to clinical, radiological results, the rate of surgical complication and the rate of successful fracture reduction.

Methods: The patients with posterior acetabulum fractures were diagnosed on basis of clinical suspicion and confirmed on x-rays and CT scans. Displaced fractures were treated surgically in lateral position through KocherLangenbeck approach and fractures were fixed with reconstruction plates and cancellous screws and results studied.

Results: Clinical grading was based on Merle d'Aubigne and Postel scoring which has been modified by Matta, According to this scale excellent to good results seen in $76.66 \%$ and fair results seen in $23.33 \%$ of cases. Radiological assessment grading according to the criteria developed by Matta, According to this criteria excellent to good radiological results are seen in $79.66 \%$ and poor results in $6.66 \%$ of cases.

Conclusions: Displaced posterior acetabular fractures treated by open reduction and internal fixation with anatomical reduction allow early mobilisation and weight bearing and gives excellent results.
\end{abstract}

Keywords: Fracture posterior column-wall acetabulum, Reconstruction-plate, Results

\section{INTRODUCTION}

The subject of acetabular fractures is one that will interest most trauma surgeons. Although posterior acetabular fractures may appear to be simple on plain radiographs, many surgeons face difficulties. They pose a challenge both in their diagnosis and their management. Open reduction and internal fixation is now the standard treatment protocol for displaced acetabulum fractures. ${ }^{1-8}$ Open reduction and fixation is a specialised work which requires training. Most posterior acetabular fractures are comminuted or they are associated with an impaction injury of the articular surface into the underlying cancellous bone along the margin of the fracture line..$^{4-6}$ The soft tissues are frequently detached from fragments at the time injury or surgery. In addition it is difficult to judge the quality of reduction and congruity of articular surface due to its three dimensional complex shape. Therefore it's of prime importance to achieve anatomical reduction during primary surgery. There are few published studies with a prolonged follow up. This case series reviews patient profile, operative techniques together with functional and radiological outcome. 


\section{METHODS}

The present study "study and results of reconstruction plating in fracture posterior column and posterior wall of acetabulum' was undertaken at the department of orthopaedics after getting ethical clearance. This study was conducted prospectively from June 2009 to June 2014 on 30 patients having fractures of posterior acetabulum which includes fracture posterior wall and fracture posterior column of acetabulum. Study duration 5 years.

\section{Inclusion criteria}

Inclusion criteria were age group between 18 to 70 years; displaced fractures of the posterior acetabulum which includes fractures of posterior column and fractures of posterior wall of acetabulum; joint incongruence with fracture posterior acetabulum caused mainly by intraarticular osteochondral fracture fragments; patient was ambulatory prior to fracture, though they may have used an aid such as a cane or a walker; anticipated medical optimalization for operation.

\section{Exclusion criteria}

Exclusion criteria were age less than 18 years in whom ossification of acetabulum is not complete and age more than 70 years; fracture of posterior acetabulum with fracture anterior column or wall of acetabulum; patients not suitable for internal fixation (i.e. severe infection around acetabulum, severe osteoarthritis, or pathologic fracture); associated comorbid conditions making patient unfit for surgery, history of suffering from myocardial infarction (MI) less than 1 year, uncontrolled hypertension and diabetes mellitus; moderate or severe cognitively impaired patients; pregnancy.

\section{The following protocol was used in management of acetabular fractures}

1. Administration of first aid on reception of the patient in casualty department.

2. Stabilization of the patient with i.e. fluids, oxygen, and blood transfusion whenever required.

3. Careful assessment of the injured limb as regards to side affected, type of fracture (closed/ compound), extent of soft tissue injury, deformity, and neurovascular status.

4. Look for shortening of the entire limb, limb position of a posterior dislocation (flexion, adduction, and internal rotation of the hip with a shortened lower extremity)

5. Musculoskeletal examination to rule out associated fractures.

6. Thorough examination of the patient to rule out head/chest/spinal and abdominal injury.

7. Primary immobilization of the injured limb and transportation of the patient to radiology department for X-rays. Patients are maintained in skeletal traction preoperatively, and reduction of the femoral head is confirmed roentgenographically.

8. The patient was then admitted to respective ward and evaluated in terms of time, mode of injury, radiological assessment with three standard plain radiographs (one AP and two oblique Judet views), a two dimensional computed tomography scan and a three dimensional computed tomography scan.

On radiological assessment all the fractures were classified according to Judet and Letournel system of classification. Then patients were selected for open reduction and internal fixation properly according to the inclusion criteria. Surgical treatment was performed as soon as the patient's general medical condition allowed.

\section{Preoperative planning}

All surgeries were performed mostly between 2 to 10 days, fracture pattern was meticulously studied and suitable approach and proper implant was selected.

\section{Preoperative preparation of the patients}

- Patients were kept nil by mouth for 6 to 8 hours before surgery.

- Blood reserved

- Preparation of whole extremity.

- Written informed consent.

- Tranquilizers H.S

- I.V. antibiotics $30 \mathrm{~min}$ before the procedure.

- Shifting the patient $30 \mathrm{~min}$ before the surgery to operation theatre.

\section{Surgical technique}

Patients were operated under spinal/general anaesthesia. Patient is placed in lateral over a radiolucent operating table. For all patients with fracture posterior acetabulum Kocher Langenbeck approach was used. It provides direct visualisation of the entire lateral aspect of the posterior column. Visualisation may be extended anterosuperiorly by dividing a portion of gluteus medius or performing a transtrochanteric osteotomy. Limited access to the quadrilateral surface can be attained by the palpating finger.

\section{Surgical sequence/reduction techniques}

- Debride edges of fracture, cancellous surfaces and recipient bed.

- "Memorize" original position of small separate osseochondral fragments, which will Aid reduction.

- Distraction of hip joint for complete visualization/ debridement.

- Utilization of femoral head as template for posterior wall. 
After reduction of the wall fragments, provisional fixation with Kirschner wires is performed, while definitive fixation is performed with cancellous screws and a contoured reconstruction plate placed from the ischium, over the retroacetabular surface onto the lateral ileum.

The reduction and screw positions are checked on C-arm image intensifier. Drain is kept and incision closed in layers and dressing is applied.

\section{Postoperative care}

\section{Immediate}

- $\quad$ N.B.M. for 4 -6 hours.

- I.V. fluids/blood transfusion.

- I.V antibiotics- cefuroxime 1gm BID, $500 \mathrm{mg}$ amikacin BID, $500 \mathrm{mg}$ metronidazole TDS and I.M inj. Diclofenac sodium 3 cc TDS were started to the patients..

- $\quad$ Active toe movements

- TPR/BP chart hourly

- Input/output chart

- Check X-ray of the operated acetabulum with three standard radiographic views i.e. A.P. view, obturator oblique view and iliac oblique view.

- Postoperatively I.V. antibiotic was given for 3 days (72 hrs), drain was removed after 48 hours, wound was checked on fifth day and accordingly patient was shifted to oral antibiotics (e.g. tab. Cefuroxime axetil $500 \mathrm{mg}$. BD for another 5 days).

\section{Mobilization protocol}

- Day 1: Static quadriceps exercises are started.

- Days 3-7: Dynamic quadriceps exercises are performed.

- Weeks 8-12: Weight bearing is limited for 8-12 weeks postoperatively.

- Week 12: Full weight bearing ambulation is permitted only after the fracture unites. One year: Return to sporting activity

- Follow up: Patients were followed up initially at 3 weeks interval for first 2 months and thereafter at 6 weekly intervals for next 6 months. All the patients were assessed clinically and radiographically.

At the final follow-up examination, functional outcomes were evaluated according to the clinical grading system developed by Merled'Aubigné and Postel as modified by Matta. ${ }^{5,6}$ The three individual scores are then summed to derive the final clinical score. According to the final scores, the clinical results were classified as excellent (18 points), good (15-17 points), fair (13-14 points), or poor (<13 points).

The radiographs were then graded according to the criteria described by Matta.
Table 1: Radiographic grading system, modified by Matta., ${ }^{1,5,6}$

Excellent normal: Appearing hip joint
Good: Mild changes, small osteophytes, moderate joint
narrowing ( $1 \mathrm{~mm})$, and minimal sclerosis
Fair: Intermediate changes, moderate osteophytes,
moderate joint narrowing $(<50 \%)$, and moderate
sclerosis
Poor: Advanced changes, large osteophytes, severe
joint narrowing $(>50 \%)$, collapse or wear of the
femoral head, and acetabular wear.

Table 2: Clinical grading system, modified by Matta. ${ }^{1,5,6}$

\begin{tabular}{|c|}
\hline $\begin{array}{ll} & \text { Pain } \\
\text { - } & 6=\text { none } \\
\text { - } & 5=\text { slight or intermittent } \\
\text { - } & 4=\text { after walking but resolves } \\
& \text { walk } \\
\text { - } & 2=\text { severe, prevents walking severe but patient is able to }\end{array}$ \\
\hline $\begin{array}{ll} & \text { Walking } \\
\text { - } & 6=\text { normal } \\
\text { - } & 5=\text { no cane but slight limp } \\
\text { - } & 4=\text { long distance with cane or crutch } \\
\text { - } & 3=\text { limited even with support } \\
\text { - } & 2=\text { very limited } \\
\text { - } & 1=\text { unable to walk }\end{array}$ \\
\hline $\begin{array}{ll} & \text { Range of motion } \\
- & 6=95-100 \% \\
\text { - } & 5=80-94 \% \\
\text { - } & 4=70-79 \% \\
\text { - } & 3=60-69 \% \\
\text { - } & 1=50-59 \% \\
& 1=<50 \%\end{array}$ \\
\hline
\end{tabular}

\section{RESULTS}

Clinical grading was based on Merle d'Aubigne and Postel scoring which has been modified by Matta (Table 3).

Table 3: Clinical grading.

\begin{tabular}{|lllll|}
\hline Result & $\begin{array}{l}\text { Posterior } \\
\text { wall }\end{array}$ & $\begin{array}{l}\text { Posterior } \\
\text { column }\end{array}$ & Total & $\%$ \\
\hline Excellent & 7 & 3 & 10 & 33.33 \\
\hline Good & 12 & 1 & 13 & 43.33 \\
\hline Fair & 7 & 0 & 7 & 23.33 \\
\hline Poor & 0 & 0 & & 0 \\
\hline
\end{tabular}

In our series excellent to good results are seen in $76.66 \%$ of patients.

Radiological assessment grading was according to the criteria developed by Matta (Table 4). 
Table 4: Radiological assessment grading.

\begin{tabular}{|lll|ll|}
\hline Results & $\begin{array}{l}\text { Posterior } \\
\text { wall }\end{array}$ & $\begin{array}{l}\text { Posterior } \\
\text { column }\end{array}$ & Total & $\%$ \\
\hline Excellent & 6 & 2 & 8 & 26.33 \\
\hline Good & 15 & 1 & 16 & 53.33 \\
\hline Fair & 3 & 1 & 4 & 13.33 \\
\hline Poor & 2 & 0 & 2 & 6.66 \\
\hline
\end{tabular}

Satisfactory results seen in $93.33 \%$ of cases and poor outcome in $6.66 \%$

Table 5: Full weight bearing.

\begin{tabular}{|lll|}
\hline Period in months & Cases & $\%$ \\
\hline <12 weeks & 0 & 0 \\
\hline 12 to 16 weeks & 20 & 66.67 \\
\hline$>$ 16 weeks & 10 & 33.33 \\
\hline
\end{tabular}

Full weight bearing was allowed in majority of our patients after 12 weeks as per their pain tolerance and radiological union.

Table 6: Union time in weeks.

\begin{tabular}{|l|l|}
\hline Weeks & No of cases \\
\hline $\mathbf{1 2}$ to 14 & 12 \\
\hline $\mathbf{1 4}$ to 16 & 23 \\
\hline $\mathbf{1 6}$ to 18 & 3 \\
\hline$>\mathbf{1 8}$ & 2 \\
\hline
\end{tabular}

Our patients united as per standard union time mostly between 12 to 18 weeks.

Table 7: Interval between trauma and surgery.

\begin{tabular}{|lll|}
\hline Interval in weeks & Cases & $\%$ \\
\hline$<\mathbf{1}$ week & 10 & 33.33 \\
\hline $\mathbf{1}$ to 2 weeks & 19 & 63.34 \\
\hline > 2 weeks & 1 & 3.33 \\
\hline Total & 30 & \\
\hline
\end{tabular}

Some patient's surgery was delayed upto 2 weeks due to anesthesia fitness issues.

Table 8: Duration of surgery.

\begin{tabular}{|lll|}
\hline Duration in days & Cases & $\%$ \\
\hline$<\mathbf{1 ~ h r}$ & 0 & 0 \\
\hline $\mathbf{1 - 2} \mathbf{~ h r}$ & 17 & 56.67 \\
\hline $\mathbf{2 - 3} \mathbf{~ h r}$ & 12 & 40 \\
\hline$>\mathbf{3 ~ h r}$ & 1 & 3.33 \\
\hline Total & 30 & \\
\hline
\end{tabular}

Majority of our surgeries required time between 2 to 3 hours.

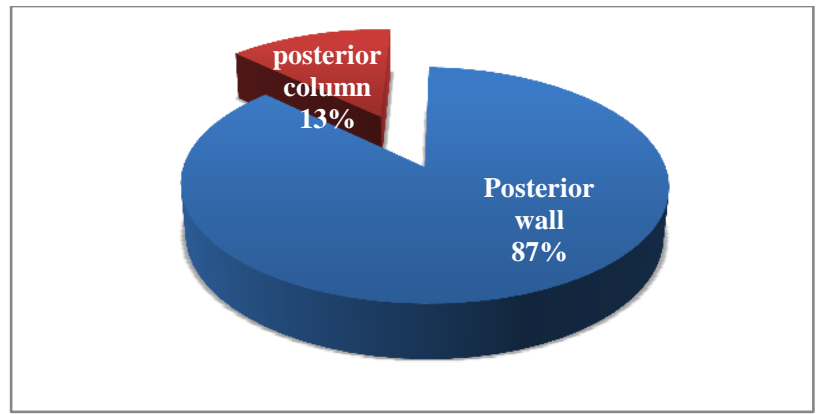

Figure 1: Type of fractures.

Posterior acetabulum wall fractures are the overall most common acetabulum fractures.

\section{Clinical case 1}
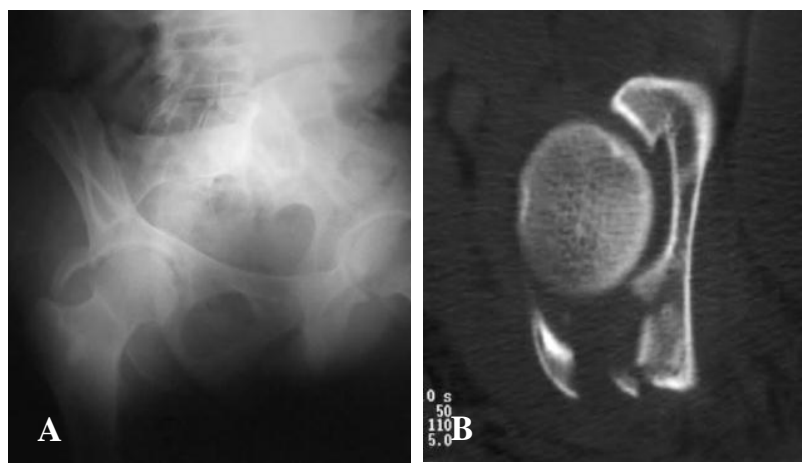

Figure 2: (A) Preoperative X-ray, (B) 2-D computed tomography.
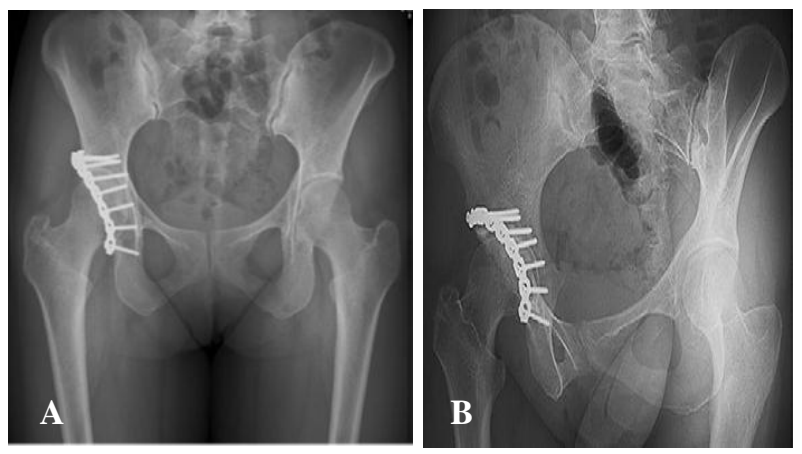

Figure 3: (A) Post-operative X-ray at 3 months, (B) Post-operative X-ray at 6 months.

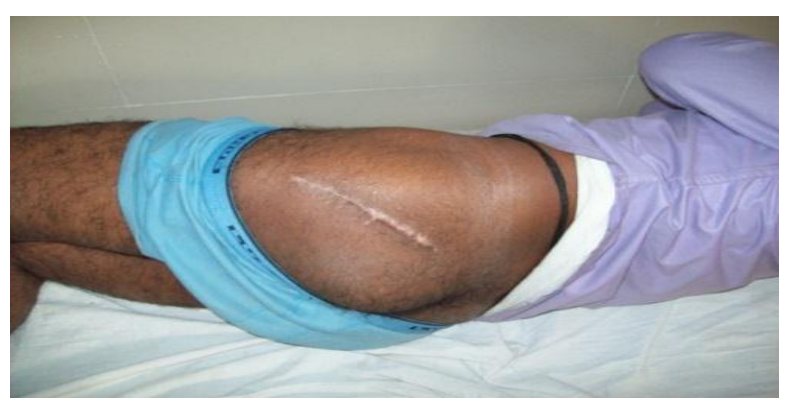

Figure 4: Healed skin incision. 


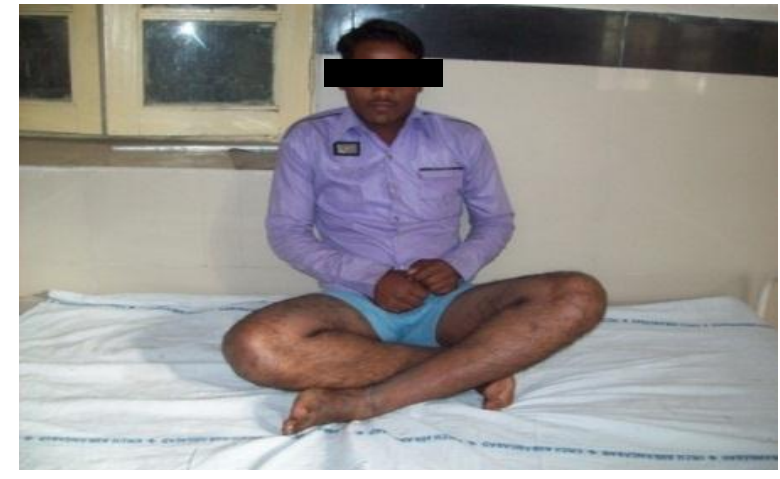

Figure 5: Cross leg sitting.

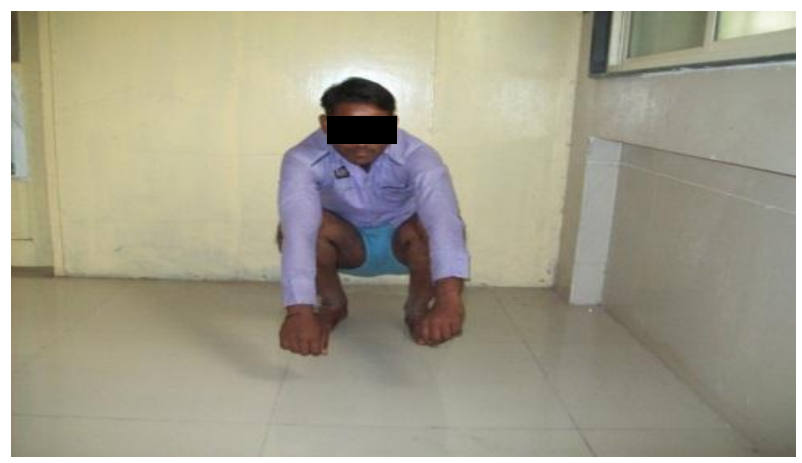

Figure 6: Patient squatting.

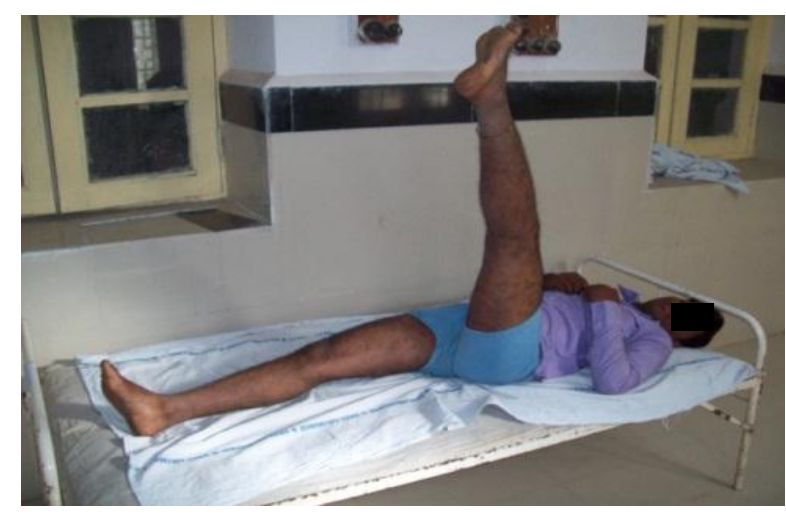

Figure 7: Straight leg raising.

\section{Clinical case 2}
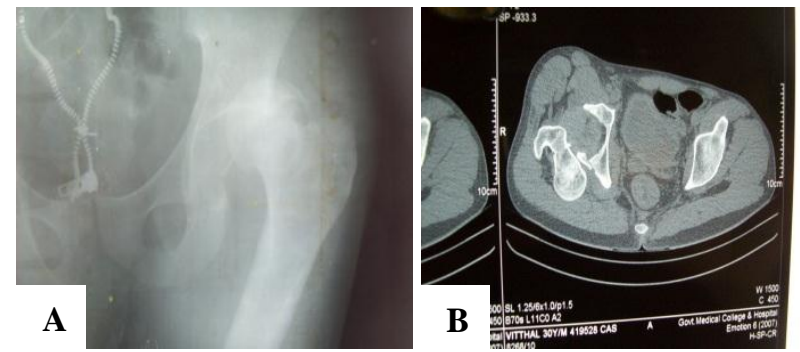

Figure 8 (A and B): Hip dislocation with fracture post acetabulum.
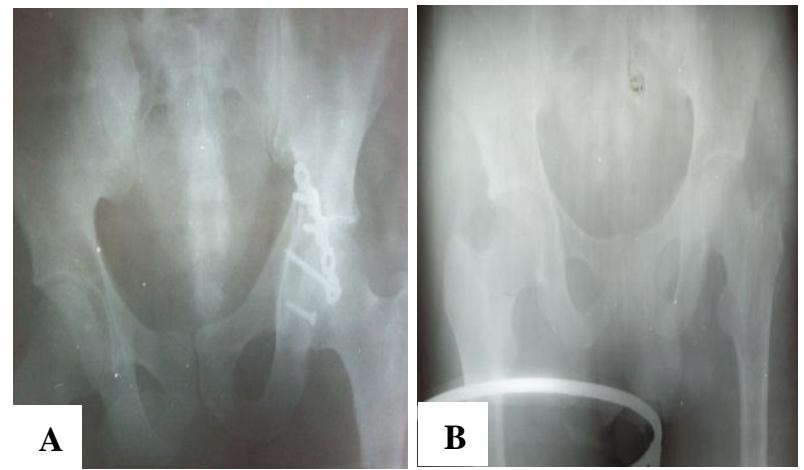

Figure 9: (A) After closed reduction; (B) Reconstruction plates and CC screws.

\section{Complications}

The 2 patients had superficial wound, all resolved with daily dressings and antibiotics and delayed mobilisation without the need of wound debridement. 3 patients had post traumatic arthritis with hip stiffness which were on physiotherapy. 2 patients had a partial sciatic neuropraxia which recovered four months after operation. All though we did not used any prophylaxis against heterotrophic ossification only 1 patient had heterotrophic ossification in the postoperative X-rays but was asymptomatic and had full range of motion. No patient had deep vein thrombosis as ankle dorsiflexion, static quadriceps exercises and knee mobilisation were started early.

\section{DISCUSSION}

In present series of 30 cases of fractures of posterior acetabulum treated primarily by reconstruction plates and cancellous screws over a period of five years from June 2009 to June 2014 with follow up period ranging from 2 months to 5 years. We evaluated our results and compared them with the result of various studies in the literature.

\section{Age and sex of patient}

Moed et al reported in their study results of operative treatment of fractures of the posterior wall of the acetabulum, the patient's ages ranged from 16 to 74 years with an average of 38 years, there were 74 male and 26 females among total of 100 patients. ${ }^{1}$

Xin et al reported treatment of posterior wall fractures of acetabulum total 31 patients 25 males and 6 females aged 19 to 59 years with mean age 40.5 years. $^{25}$

Petsatodis et al found in their study, surgically treated acetabular fractures via a single posterior approach with a follow-up of 2-10 years, 50 patients 32 male and 18 female, aging from 18 to 71 years with mean age 37.8 years. $^{27}$ 
In the present study the ages range from 18 to 65 years. The average age of the patient is 34 years. The most common age group was 30 to 39 years, there were 27 $(90 \%)$ were males and $3(10 \%)$ were females. The results found are comparable to the previous standard studies.

\section{Mode of trauma}

Berton et al stated in their study, results of operative treatment of fractures of the posterior wall of the acetabulum, 89 out of 100 cases were caused by road traffic accident 6 by fall from height and 3 by sports related activity. ${ }^{1}$

Ebraheim et al informed reconstruction of comminuted posterior wall fractures using the buttress technique: a review of 32 fractures, in this study of 32 patients 28 were from road traffic accident, 2 due fall from height and 2 due to snow board injuries. ${ }^{2}$

Kim et al reported reconstruction of acetabular posterior wall fractures, in this series of 33 patient 26 had road traffic accidents, 5 had fall from height, 2 had sport related trauma. ${ }^{3}$

In the present series out of 30 patients 28 had road traffic accidents, 2 had fall from height, the most common mode of trauma was RTA in $28(93 \%)$. The results were found similar to previous studies.

\section{Type of fractures}

Kim et al in their findings reported reconstruction of acetabular posterior wall fractures, in this series of 33 patient, according to the Letournel- Judet system there were $21(63.6 \%)$ simple posterior wall fractures 12 $(36.4 \%)$ were complex fractures associated with other types of fractures. ${ }^{3}$

Lim et al described operative treatment of acetabular fractures, in this series most of the cases 14 out of 23 involved posterior wall fractures. ${ }^{5}$

In our present series posterior wall fractures were seen in $26(87 \%)$ of patients and posterior column fractures were seen in $4(13 \%)$ of cases. The results match previous studies.

\section{Associated fractures}

Kim et al found reconstruction of acetabular posterior wall fractures, in this series of 33 patient 12 patients $(37 \%)$ had fractures in their extremities (9 lower and 3 upper) that required surgical treatment. ${ }^{3}$

Bassi et al described open reduction and internal fixation of posterior wall acetabular fractures. This study had 23 patients having fractures other than the fractures of acetabulum. ${ }^{4}$
In our series we had 4 cases of fractures to the extremities with 2 cases of hip dislocation.

\section{Interval between trauma and surgery/duration of surgery}

Moed et al stated in their study results of operative treatment of fractures of the posterior wall of the acetabulum, in this study surgical treatment was performed as soon as the patient's general medical condition allowed, sometimes resulting in delays in treatment. In addition, there were some delays in treatment related to transfer of the patient from a referring institution. The overall time from injury to surgery averaged seven days (range, zero to twenty days). ${ }^{1}$

Ebraheim et al found reconstruction of comminuted posterior wall fractures using the buttress technique, in this study the patients were taken up for surgery as soon as their general medical condition permitted. The time from injury to operation averaged 4 days (range of 126 days). The average duration of surgery was $2.34 \mathrm{~h}$ (range 1.38-3.54 hrs). ${ }^{2}$

Kim et al reported Reconstruction of acetabular posterior wall fractures 19 patients underwent surgery for posterior wall fracture within 1 week after injury, 10 underwent surgery between 1 and 2 weeks and 4 underwent surgery after 2 weeks. $^{3}$

Wei-chun et al informed surgical treatment of acetabular posterior wall fracture with hip dislocation, in this study the operation time averaged 60 to 120 minutes $(90 \pm 30) .{ }^{30}$

In our present series, $63.34 \%$ cases were operated between 1 to 2 weeks. Average interval between trauma and surgery was 8.46 days. Average duration of surgery was $1 \mathrm{hr}$ and $55 \mathrm{~min}$. 56.67\% cases were finished within $2 \mathrm{hrs}$ and $40 \%$ cases were finished within 2 to 3 hours. These results match to the various studies conducted for posterior acetabulum fractures.

\section{Full weight bearing}

Moed et al stated in their study results of operative treatment of fractures of the posterior wall of the acetabulum, progression to full weight-bearing was individualized depending upon tolerance to pain after 12 weeks. ${ }^{1}$

Ebraheim et al found reconstruction of comminuted posterior wall fractures using the buttress technique, in this study full weight bearing was started at 3 months. ${ }^{2}$

Lee et al stated surgical treatment of posterior fracturedislocation of the acetabulum: Five-year follow up, in this study full weight-bearing was individualized and was allowed 8 weeks after the operation. ${ }^{6}$ 
In the present series $20(66.67 \%)$ cases started full weight bearing in 12 weeks, and $10(33.33 \%)$ cases started full weight bearing in 16 weeks due to superficial wound infection and associated injuries.

\section{Complications}

Moed et al found in their study results of operative treatment of fractures of the posterior wall of the acetabulum, 1 deep wound infection 2 superficial wound infection, deep vein thrombosis seen in 7 patients, no patient had severe heterotrophic ossification, no patient had intra articular hardware, no patient had iatrogenic sciatic nerve palsy though 2 patients had post traumatic nerve palsies. ${ }^{1}$

Moed et al descibed open reduction and internal fixation of posterior wall fractures of the acetabulum, in this series complications included deep wound infection (1), deep vein thrombosis, (7), and revision surgery to redirect an errant screw (1). ${ }^{13}$

Petsatodis et al, in this study Surgically treated acetabular fractures via a single posterior approach postoperative complications included 2 peroneal nerve palsies and 3 wound infections and late complications included 1 patient with avascular necrosis of the femoral head (ANFH), 5 patients with heterotopic ossification. ${ }^{27}$

Baumgaertner reported fractures of the posterior wall of the acetabulum, in this series complications include sciatic nerve injury ( 3 to $18 \%$ ), heterotrophic ossification ( 7 to $20 \%$ ), and osteonecrosis of the femoral head (5 to $8 \%)^{31}$

In the present series, 3 patients had superficial wound, all resolved with daily dressings and antibiotics and delayed mobilisation without the need of wound debridement. 2 patients had post traumatic arthritis with hip stiffness which were on physiotherapy. 1 patient had a partial sciatic neuropraxia which recovered four months after operation. All though we did not used any prophylaxixs against heterotrophic ossification only 1 patient had heterotrophic ossification in the postoperative X-rays but was asymptomatic and had full range of motion. No patient had deep vein thrombosis as ankle dorsiflexion, static quadricep exercisis and knee mobilisation were started early.

\section{Radiographic grading results}

Ebraheim et al found reconstruction of comminuted posterior wall fractures using the buttress technique. The postoperative reduction was graded as anatomical in 28 patients $(88 \%)$ and imperfect in 4 patients $(12 \%){ }^{2}$

Kim et al, in their series, according to the radiologic criteria of Matta, 10 patients (30.3\%) had excellent results, 14 (42.4\%) had good results, $4(12.1 \%)$ had fair results and $5(15.2 \%)$ were poor. ${ }^{3}$

Bassi et al stated open reduction and internal fixation of posterior wall acetabular fractures, in this series the postoperative radiographs were assessed for adequacy of reduction. It was graded as excellent in 16 hips (35\%), good in 18 hips $(40 \%)$, fair in seven hips (16\%) and poor in four (9\%) hips. ${ }^{4}$

Moed et al informed open reduction and internal fixation of posterior wall fractures of the acetabulum, in this series. Radiographic results were excellent in 79 hips $(84 \%)$, good in four $(4 \%)$, fair in two $(2 \%)$, and poor in nine $(10 \%) .^{13}$

In the present series excellent to good radiological results were seen in $79.66 \%$, and poor in $6 \%$. These results are comparable to other standard studies conducted for posterior acetabular fractures.

\section{Clinical outcome}

Ebraheim et al found that reconstruction of comminuted posterior wall fractures using the buttress technique the results for clinical outcome according to modified Merle d'Aubigne and Postel scoring system were as follows: excellent $11(34 \%)$, very good $9(28 \%)$, good $4(12 \%)$, fair $3(9 \%)$ and poor $5(15 \%){ }^{2}$

Kim et al discussed in their study, reconstruction of acetabular posterior wall fractures in this series. The D'Aubigne and Postel scores at the final follow-up visit were as follows: excellent and very good in 15 patients $(45.5 \%)$, good in $5(15.2 \%)$, fair in $3(9.1 \%)$, and poor in $10(30.3 \%){ }^{3}$

Bassi et al reported open reduction and internal fixation of posterior wall acetabular fractures: in this series the final functional outcome as assessed by Merle-deAubigne and Postel's modified criteria, was excellent in $13(29 \%)$, good in $17(38 \%)$, fair in seven $(16 \%)$ and poor in eight $(18 \%){ }^{4}$

Moed et al stated open reduction and internal fixation of posterior wall fractures of the acetabulum, in this series). Clinical outcome was graded as excellent in 34 patients $(36 \%)$, good in $49(52 \%)$, fair in two $(2 \%)$, and poor in nine $(10 \%) .^{13}$

In the present series excellent to good clinical results were seen in $76.66 \%$, and fair in $23.33 \%$ of cases. The poor results were observed due to imperfect fracture reduction as these patients were operated after 2 weeks and they improved showing fair results.

Thus the conclusion is reconstruction of the posterior acetabular fracture with open reduction and internal fixation produces good to excellent results in majority of 
patients with acceptable rate of complication. They provide a stable fixation with good joint congruency of the hip joint amenable to early range of motion and weight bearing. Therefore our study establishes that the intrarticular posterior acetabulum fractures are best treated operatively and we recommend that open reduction and internal fixation of posterior acetabular fractures as the treatment of choice in displaced fractures.

Funding: No funding sources Conflict of interest: None declared

Ethical approval: The study was approved by the institutional ethics committee

\section{REFERENCES}

1. Moed BR, WillsonCarr SE, Watson JT. Results of Operative Treatment of Fractures of the Posterior Wall of the Acetabulum. J Bone Joint Surg Am. 2002;84:752-8.

2. Ebraheim NA, Patil V, Liu J, Sanford CG, Haman SP. Reconstruction of comminuted posterior wall fractures using the buttress technique: a review of 32 fractures. Int Orthop. 2007;31(5):671-5.

3. Kim HT, Ahn JM, Hur JO, Lee JS, Cheon SJ. Reconstruction of Acetabular Posterior Wall Fractures. Clin Orthop Surg. 2011;3(2):114-20.

4. Bassi JL, Dattal C, Mahindra P, Singh N. Open Reduction And Internal Fixation Of Posterior Wall Acetabular Fractures: A Study Of 45 Cases. J Orthop. 2007;4(1):17

5. Lim HH, Tang CL, Krishnamurty S. Operative Treatment Of Acetabular Fractures. Singapore Med J. 1994;35:173-5.

6. Lee CS, Chen CL, Han PW, Shiuan PC, Wang CM, Lo WH. Surgical treatment of posterior fracturedislocation of the acetabulum: Five-year follow up, Copyright_2011, Taiwan Orthopaedic Association. Elsevier Taiwan LLC; 2011.

7. Cano-Luisa P, Marcos-Moralesb F, Ricón-Recareyb J, Torresb AL. Results of the Surgical Treatment of Acetabular Fractures. Ortop Traumatol. 2006;50:100-10.

8. Petsatodes G, Christoforides J, Antonarakos P. Surgical Treatment Of Acetabular Fractures. Thessaloniki, Greece. 2000: 55131.

9. Kregor PJ, Reilly MC, Stover MD, Vrahas MS, Moed BR. Current Management of Posterior Wall Fractures of the Acetabulum. Am Academy Orthopaed Surg. 2011.

10. Moed BR, Carr SE, Watson JT. Open reduction and internal fixation of posterior wall fractures of the acetabulum. Clin Orthop Relat Res. 2000;(377):5767.

11. Moed BR, Carr SE, Gruson KI, Watson JT, Craig JG. Computed tomographic assessment of fractures of the posterior wall of the acetabulum after operative treatment. J Bone Joint Surg Am. 2003;85(3):512-22.
12. Moed BR, Mc Michael JC. Outcomes of posterior wall fractures of the acetabulum. Surgical technique. J Bone Joint Surg Am. 2008;90(2):87107.

13. Dean DB, Moed BR. Late salvage of failed open reduction and internal fixation of posterior wall fractures of the acetabulum. J Orthop Trauma. 2009;23(3):180-5.

14. Gansslen A, Steinke B, Krettek C. Internal fixation of acetabular posterior wall fractures. Oper Orthop Traumatol. 2009;21(3):283-95.

15. Saterbak AM, Marsh JL, Nepola JV, Brandser EA, Turbett T. Clinical failure after posterior wall acetabular fractures: the influence of initial fracture patterns. J Orthop Trauma. 2000;14(4):230-7.

16. Olson SA, Bay BK, Pollak AN, Sharkey NA, Lee T. The effect of variable size posterior wall acetabular fractures on contact characteristics of the hip joint. $\mathrm{J}$ Orthop Trauma. 1996;10(6):395-402.

17. Xin Q, LIU Jian-guo, GONG Yu-bao, YANG Chen, LI Shu-qiang, FENG Wei. Treatment of posterior Wall fractures of acetabulum. Chinese J Traumatol. 2009;12(2):113-7.

18. Kiamura AI, Tooru I, Masano Y, Hiroyuki H, Hiroshi N. Clinical result of surgical treatment for posterior wall fracture of acetabulum; Central Japan. J Orthopaedic Surg Traumatol. 2005;48(1):185-6.

19. Petsatodis G, Antonarakos P, Chalidis B, Padadopoulos P, Christoforidis J, Pournaras J. Surgically treated acetabular fractures via a single posterior approach with a follow-up of 2-10 years. Injury. 2007;38(3):334-43.

20. Chen HW, Zhao GS. Surgical treatment of acetabular posterior wall fractures. Zhongguo $\mathrm{Gu}$ Shang. 2008;21(9):674-5.

21. Osgood, Greg M. Posterior wall acetabular fractures: update on surgical indications, fixation techniques and outcome measurements. Lippincott Williams \& Wilkins Inc; 2009.

22. Wei-Chun H, Yong-Jin Z, Xu F. Surgical treatment of acetabular posterior wall fracture with hip dislocation. CNKI: SUN:LCGK.0.200903-037.

23. Baumgaertner MR. Fractures of the posterior wall of the acetabulum, @ 1999 by the American Academy Of Orthopaedic Surgeon, 1999.

24. Tadros AMA, Brien O, Peter, Pierre G. Fixation of Marginal Posterior Acetabular Wall Fractures Using Locking Reconstruction Plates And Monocortical Screws. J Trauma-Injury Infection Critical care. 2010;68(2):478-80.

25. Pantazopoulos T, Nicolopoulos CS, Babis GC, Theodoropoulos T. Surgical treatment of acetabular posterior wall fractures. Injury. 1993;24(5):319-23.

26. Won CH, Kim YM, Park KJ, Jeong KI, Lee SN. Results of Treatment for Acetabular Fracture involving Posterior Wall. J Korean Soc Fract. 1999;12(4):754-60.

27. Triantaphillopoulos PG, Panagiotopoulos EC, Mousafiris C, Tyllianakis M, Dimakopoulos $\mathrm{P}$, Lambris EE. Long-term results in surgically treated 
acetabular fractures through the posterior approaches. J Trauma. 2007;62(2):378-82.

28. Matta JM. Fracture of the acetabulum: accuracy of reduction and clinical results in patients managed operatively within three weeks after the injury. J Bone Joint Surg Am. 1996;78(11):1632-45.

29. Matta JM, Anderson LM, Epstein HC, Hendricks P. Fractures of the acetabulum. A retro-spective analysis. Clin Orthop Related Res. 1986;205:23040.
30. Matta JM, Mehne DK, Roffi R. Fractures of the acetabulum. Early results of a prospectivestudy. Clin Orthop Rel Res. 1986;205:241-50.

Cite this article as: Kachnerkar NI, Markade P. Study and results of reconstruction plating in fracture posterior column and posterior wall of acetabulum. Int J Res Orthop 2017;3:1104-12. 